\title{
Estimating COVID-19-Related Infections, Deaths, and Hospitalizations in Iran Under Different Physical Distancing and Isolation Scenarios
}

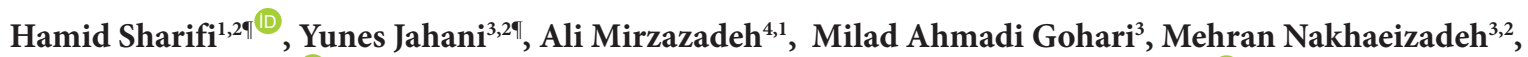

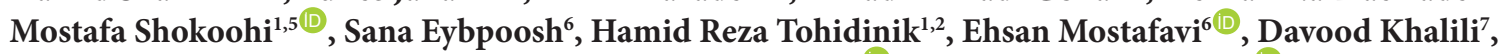 \\ Seyed Saeed Hashemi Nazari ${ }^{8}$, Mohammad Karamouzian ${ }^{1,9} \mathbb{D}$, Ali Akbar Haghdoost ${ }^{3,1 *} \mathbb{D}$
}

\begin{abstract}
Background: Iran is one of the first few countries that was hit hard with the coronavirus disease 2019 (COVID-19) pandemic. We aimed to estimate the total number of COVID-19 related infections, deaths, and hospitalizations in Iran under different physical distancing and isolation scenarios.

Methods: We developed a susceptible-exposed-infected/infectious-recovered/removed (SEIR) model, parameterized to the COVID-19 pandemic in Iran. We used the model to quantify the magnitude of the outbreak in Iran and assess the effectiveness of isolation and physical distancing under five different scenarios (A: $0 \%$ isolation, through E: $40 \%$ isolation of all infected cases). We used Monte-Carlo simulation to calculate the 95\% uncertainty intervals (UIs).

Results: Under scenario A, we estimated 5196000 (UI 1753000-10220000) infections to happen till mid-June with 966000 (UI 467800-1702000) hospitalizations and 111000 (UI 53400-200000) deaths. Successful implantation of scenario E would reduce the number of infections by $90 \%$ (ie, 550000 ) and change the epidemic peak from 66000 on June 9, to 9400 on March 1, 2020. Scenario E also reduces the hospitalizations by $92 \%$ (ie, 74500 ), and deaths by $93 \%$ (ie, 7800).

Conclusion: With no approved vaccination or therapy available, we found physical distancing and isolation that include public awareness and case-finding and isolation of $40 \%$ of infected people could reduce the burden of COVID-19 in Iran by $90 \%$ by mid-June.

Keywords: COVID-19, Modeling, Physical Distancing, Isolation, Iran

Copyright: @ 2022 The Author(s); Published by Kerman University of Medical Sciences. This is an open-access article distributed under the terms of the Creative Commons Attribution License (https://creativecommons.org/licenses/ by/4.0), which permits unrestricted use, distribution, and reproduction in any medium, provided the original work is properly cited.

Citation: Sharifi H, Jahani Y, Mirzazadeh A, et al. Estimating COVID-19-related infections, deaths, and hospitalizations in Iran under different physical distancing and isolation scenarios. Int J Health Policy Manag. 2022;11(3):334343. doi:10.34172/ijhpm.2020.134
\end{abstract}

Article History:

Received: 7 May 2020 Accepted: 14 July 2020 ePublished: 1 August 2020
'Both authors contributed equally to this paper.

*Correspondence to Ali Akbar Haghdoost Email:

ahaghdoost@gmail.com, ahaghdoost@kmu.ac.ir

\section{Key Messages}

Implications for policy makers

- With no interventions, over 5 million severe acute respiratory syndrome coronavirus 2 (SARS-CoV-2) infections, 1 million hospitalizations, up to 200000 deaths could happen in Iran until mid-June.

- Case-finding and isolation of $40 \%$ of infected people can reduce the burden of coronavirus disease 2019 (COVID-19) in Iran by $90 \%$ by midJune.

- It seems the burden of the epidemic in Iran is substantial, but Iran might have sufficient hospital bed capacity for COVID-19 based on the most probable scenarios.

Implications for the public

With no effective vaccination or treatment at hand, advocating and enforcing physical distancing and isolation along with public education on prevention measures could significantly reduce the burden of coronavirus disease 2019 (COVID-19) in Iran. 


\section{Background}

The coronavirus disease 2019 (COVID-19) was declared a pandemic on March 11, 2020, and the disease is has spread around the globe. The risk is relatively low for the general population, although people aged 65 years and over, those with suppressed immune systems, and people with underlying medical conditions (eg, cardiovascular or respiratory diseases) are at increased risk of adverse outcomes. The infection fatality rate (IFR) of the infection is estimated to be around $2 \%$ (95\% CI: $2 \%-3 \%$ ) and as of June 11, 2020, a total number of 7480281 confirmed cases, 3794453 recovered cases, and 419472 deaths have been reported worldwide. ${ }^{1}$ Iran is one of the hardest hit countries by COVID-19 and has been struggling with controlling the disease for several months. The first confirmed cases of COVID-19-related deaths were reported on February 19 in the city of Qom; $200 \mathrm{~km}$ away from Iran's capital city of Tehran. As of June 5, 2020, a total number of 169425 confirmed cases, 132038 recovered cases, and 8209 deaths have been reported and COVID-19 has spread to all of its provinces ${ }^{2}$; figures that are highest across the Eastern Mediterranean region. ${ }^{3}$

The susceptible-exposed-infected/infectious-recovered/ removed (SEIR) model provides a mathematical framework to explain the spread of infectious diseases and has been previously used for estimating the epidemiological parameters of several infectious diseases such as measles, Ebola, and influenza.-6 SEIR could also help evaluate the impact of implementing various interventions (eg, isolation and physical distancing policies) aimed at controlling the pandemic growth and flattening the epidemic curve. Physical distancing control measures are policies that aim to minimize close contacts within communities and include individuallevel (eg, quarantine, isolation) and community-level (eg, closure of educational and recreational settings, non-essential businesses, and cancellation of public/mass/crowded gatherings) approaches. ${ }^{7,8}$

In Iran, the physical distancing and isolation interventions were scaled up in late February and early March by nationwide closure of schools, cancellation of sports events and Friday or congregational prayers as well as the closure of all nonessential services, tourism sites, and shopping malls (Figure 1). Iran also closed its holy shrines in Mashhad and Qom in midMarch. Moreover, while there were no mandatory shelter-inplace or lockdown orders, people were encouraged to stay at home. People were also asked to avoid non-essential travels during the new year holidays (ie, Nowruz) from March 19 to 26; however, no restrictions for domestic or international travels were imposed. ${ }^{9}$ Despite implementing various physical distancing control measures, our understanding of their impact on the magnitude of COVID-19-related new infections, hospitalizations, and deaths remains limited. In this study, we aim to provide an estimate of these epidemiological parameters and approximate the peak date of the epidemic in Iran under different physical distancing and isolation scenarios. These estimates are of particular importance for COVID-19-related health policy, planning, and financing purposes in Iran.

\section{Methods \\ Model Description}

We developed a compartmental model to estimate the total number of COVID-19 patients, hospitalizations and deaths in Iran as well as its capital city of Tehran (Figure 2). We used an extended SEIR model that divides the target populations (ie, Iran and Tehran as the capital) into different compartments. The conceptual framework of the COVID-19 transmission model is presented in Supplementary file 1. In brief, we considered the following compartments: (a) susceptible, referring to the total number of individuals (ie, hosts) who have been susceptible to COVID-19. We assumed the entire population as susceptible in our model; $(b)$ exposed, referring to individuals who are exposed to COVID-19 while they are asymptomatic and not yet infectious; (c) infected, referring to infected people who demonstrate clinical symptoms after their incubation period and have the potential to transmit the disease to other susceptible individuals; and $(d)$ recovered/

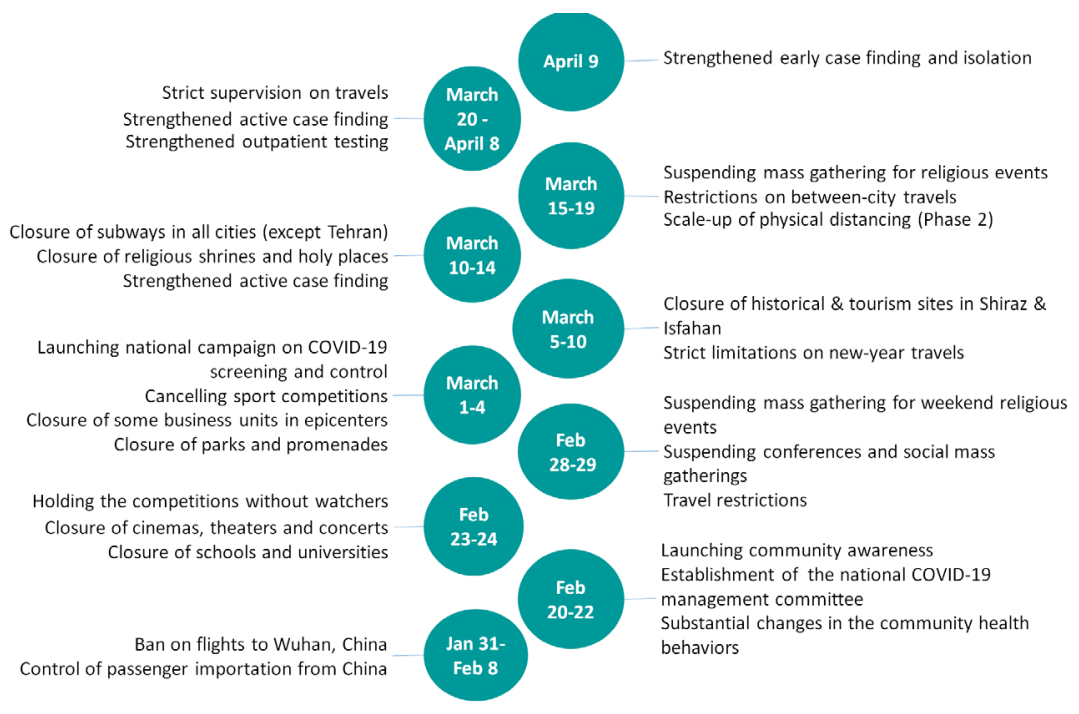

Figure 1. Iran's Interventions Aimed at Controlling the COVID-19 Epidemic Since the Beginning of the Outbreak. Abbreviation: COVID-2019, coronavirus disease 2019. 


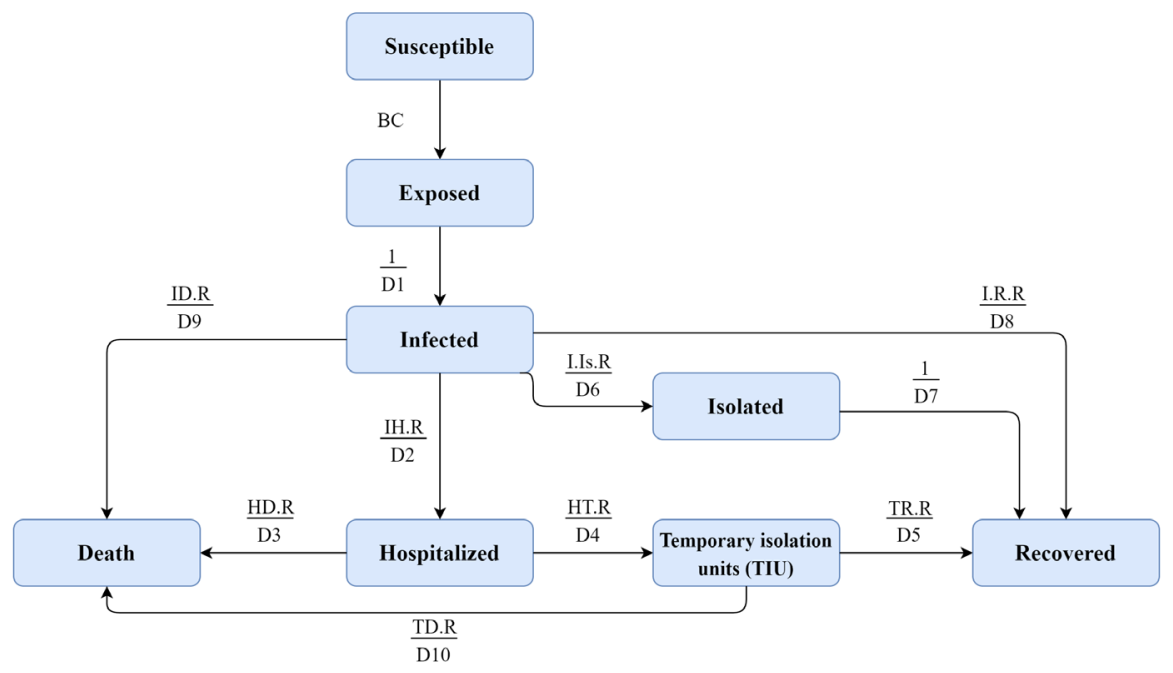

Figure 2. The SEIR Conceptual Model From Susceptible to Recovery or Deaths. Abbreviation: SEIR, susceptible-exposed-infected/infectious-recovered/removed.

removed, depending on the severity of the disease. We assumed that the infected people will $(i)$ be recovered and immune from re-infection and therefore, no longer transmit the infection, (ii) have mild to moderate clinical symptoms and follow home-isolation guidelines without the need to be hospitalized, or (iii) have severe clinical symptoms and require hospitalization. These individuals would either be recovered or die and therefore, removed from the model. Monte Carlo method was used to estimate the $95 \%$ uncertainty intervals (UIs). To do this, we used the statistical distribution of a set of parameters obtained from both the existing evidence and expert opinion (Please see Table S1, Supplementary file 2). Data were analyzed using Vensim DSS 6.4E software.

\section{Model Parameters and Calibrations}

Based on the country's official reports and available epidemiological data, January 21, 2020 was considered as the initial day of the COVID-19 outbreak in Iran. We used several parameters as model inputs and obtained their values from a comprehensive literature review and published articles in relation to COVID-19, as well as relevant parameters derived from estimates in similar epidemics, in particular, H1N1 influenza. ${ }^{10}$ We first shared the initial values of the parameters with Iran's national and scientific committees and experts, and made the necessary adjustments, accordingly. We compared the revised values of these parameters with the literature as well as the epidemic pattern in Iran. We then made the final revisions for the values of the parameters used as the extended SEIR model inputs. Please see Tables S1 and S2 in Supplementary file 2 for more details.

The impact of seasonality was considered in calculating the transmission probability (ie, beta coefficient) of the disease, indicating the potential for some level of change in transmissibility of the virus from one season to another. ${ }^{10}$ Therefore, we assumed that COVID-19 might behave the same as influenza where the transmission of the virus may be reduced by approaching warm seasons (ie, spring and summer). We then considered the end of December in winter with the highest transmission probability and the end of
June in summer with the least transmission probability. The minimum and maximum values of the seasonal changes were considered to be 0.02 and 0.045 , respectively. A timevarying state was considered for the effective contact rate (ie, parameter C). We first incorporated the value of 14 in model for Tehran and 13 in the national model in the early weeks of the epidemic. ${ }^{11-15}$ After the announcement of the epidemic by health officials, multiple public health measures were implemented as a response to the epidemic to reduce contact and transmission rates in the public. Approaching the assumed end of the epidemic, we considered the value of 5 for the contact rate parameter with some fluctuations due to Nowruz holidays which overlapped with this period. Please see Table S2 in Supplementary file 2 for more details. Five possible scenarios were considered for isolation of the infected cases (Table 1).

\section{Visual Calibration}

As the number of infections and hospitalizations were largely underestimated, we calibrated the models using daily reported deaths. Daily reported deaths were depicted in contrast to the number of estimated cases in each scenario.

\section{Reproduction Number}

Basic reproduction number $\left(\mathrm{R}_{0}\right)$ defines the average number of secondary infections caused by each infected case in a population that all individuals are susceptible. ${ }^{16,17}$ Effective reproductive number $\left(\mathrm{R}_{\mathrm{e}}\right)$ is a particular threshold in epidemiology because the impact of interventions are shown by this index. We calculated the effective reproduction number $\left(\mathrm{R}_{\mathrm{e}}\right)$ in each stage using the generation matrix method. ${ }^{18}$ We presented how to calculate $\mathrm{R}_{\mathrm{e}}$ formulas in Supplementary file 3.

$$
R_{e}=\frac{\beta(t) * C(t)}{\left(\frac{I . I S . R}{D 6}+\frac{I \cdot R \cdot R}{D 8}+\frac{I H . R}{D 2}+\frac{I D \cdot R}{D 9}\right)}
$$

Infection Fatality Rate

The IFR was calculated using this formula ${ }^{19,20}$ : 
Table 1. Different Isolation Scenarios for Estimation of COVID-19-Related Infections, Hospitalizations, and Deaths in Iran

\begin{tabular}{|c|c|}
\hline Isolation Scenario & Description \\
\hline Scenario A & Isolation for the entire period of the epidemic was considered to be $0 \%$ (ie, worst-case scenario). \\
\hline Scenario B & $\begin{array}{l}\text { Prevention policies were encouraged and the overall mean of isolation for the entire period of the epidemic was considered to be } \\
10 \% .\end{array}$ \\
\hline Scenario C & $\begin{array}{l}\text { Isolation was considered to be } 10 \% \text { from January } 21 \text { to February } 19,15 \% \text { after the initiation of the epidemic from February } 20 \text { to } \\
\text { March } 10 \text {, and } 20 \% \text { from March } 11 \text { to June } 19,2020 \text {. These policies correspond to the minimal possible interventions of the health } \\
\text { system, behaviour change of the public, and containment strategies. }\end{array}$ \\
\hline Scenario D & $\begin{array}{l}\text { Isolation was considered to be } 10 \% \text { from January } 21 \text { to February } 19,15 \% \text { after the initiation of the epidemic from February } 20 \text { to } \\
\text { March 10, and finally } 30 \% \text { from March } 11 \text { to June } 19,2020 \text {, which are the results of the moderate possible interventions of the } \\
\text { enhanced health system, social and behavioural change of the public (eg, physical distancing, hand washing), and containment } \\
\text { strategies (eg, closing schools and universities). }\end{array}$ \\
\hline Scenario E & $\begin{array}{l}\text { Isolation was considered to be } 10 \% \text { from January } 21 \text { to February } 19,15 \% \text { after the initiation of the epidemic from February } 20 \text { to } \\
\text { March } 10 \text {, and finally } 40 \% \text { from March } 11 \text { to June } 19,2020 \text {. These policies correspond to the maximum possible interventions of the } \\
\text { health system, behaviour change of the public, and containment strategies. }\end{array}$ \\
\hline
\end{tabular}

Abbreviation: COVID-2019, coronavirus disease 2019.

$\mathrm{IFR}=\frac{\text { Number of deaths due to COVID-19 }}{\text { Total number of actual infections with COVID-19 }} * 100$

\section{Results}

Validation of the Model

As seen in Figure 3, the observed deaths are close to the estimated cases in scenario C, D, and E. As the sensitivity of the disease surveillance systems across the country were low at the begging of the epidemic and during the first three weeks, the model predicted higher number of deaths than the official reports between 19 February to 10 March.

\section{Expected Number of Infected Cases}

Iran: Under scenario A, the epidemic would peak on June 9 at around 66000 (95\% UI: 15600-145000) new infected cases per day. Total number of infected cases by June 19 is expected to be 5196000 (95\% UI: $1753000-10220000$ ). Under scenario B, the peak would occur on April 30, 2020 at around 16500 (95\% UI: 5400-35000) infected cases a day; a total of 1643300 (95\% UI: 603 400-3 380000) infections would occur by June 19,2020 . Under scenario $C$, the peak would occur on 31 March at around 10700 (95\% UI: 4600-20 000) infected cases a day; a total of 949600 (95\% UI: 368 000-1960 000) infections would occur by June 19, 2020. The number of infected cases at the peak time under scenario D (9400 cases on March 1) and scenario E (9400 cases on March 1) are decreased further. The total number of infected cases by June 19, 2020 under scenario D (689000 cases on March 1, 2020) and scenario E (550000 cases on March 1, 2020) are decreased further.

Tehran: Under scenario A, the number of new cases per day
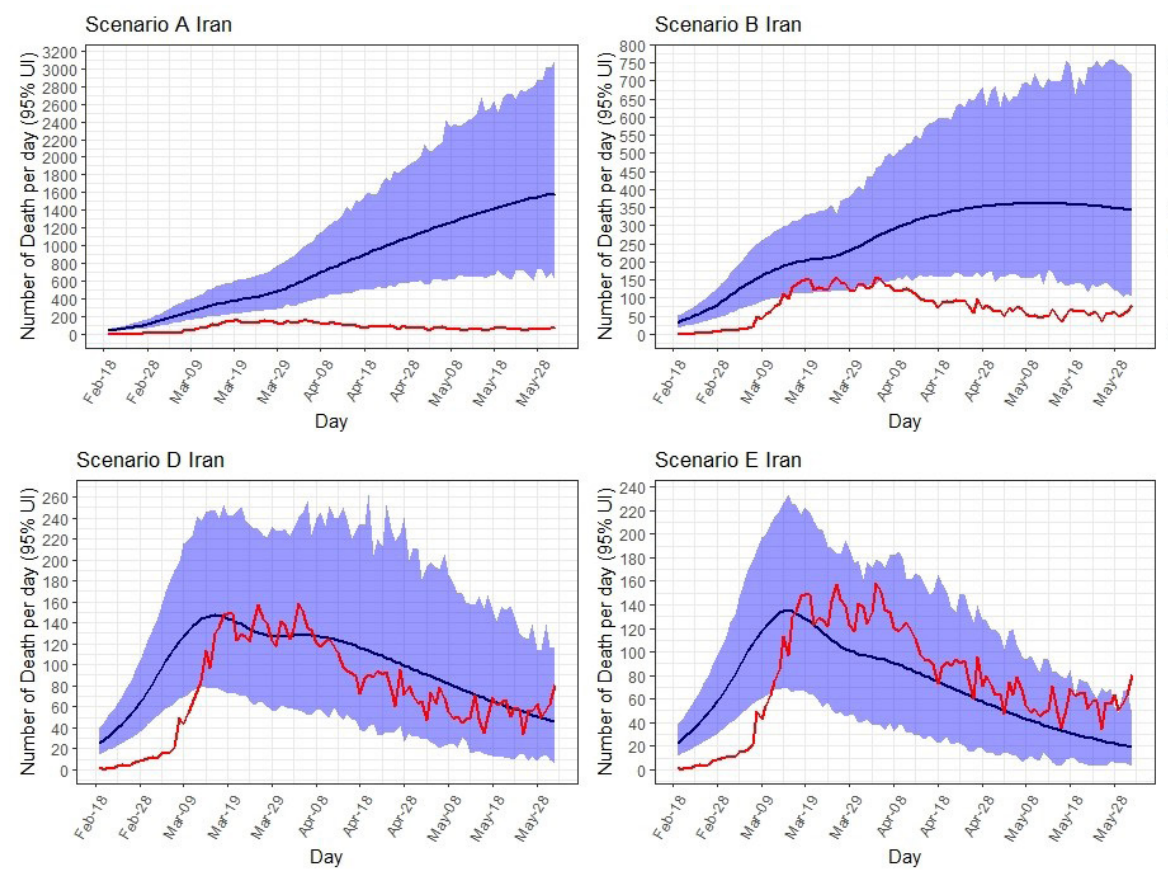

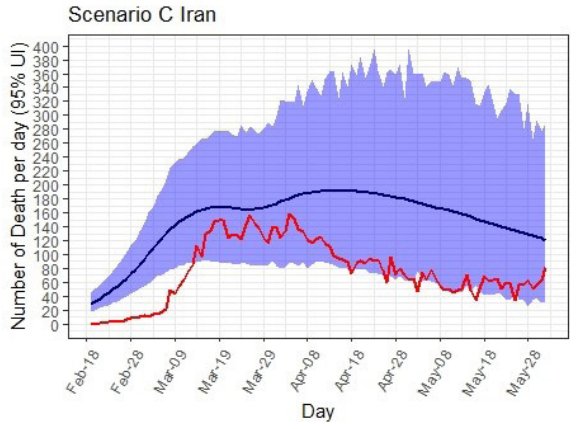

Day

Figure 3. Daily Observed Deaths in Comparison of the Reported Deaths in the National Model in 5 Scenarios. The blue area shows Uls for the estimated deaths. Abbreviation: UI, uncertainty interval. 

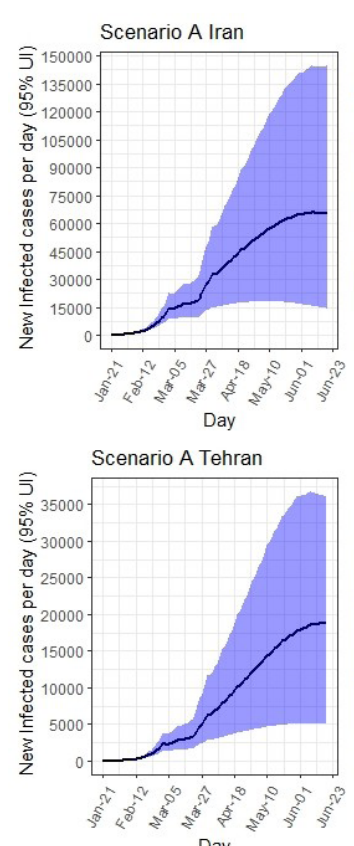

Day
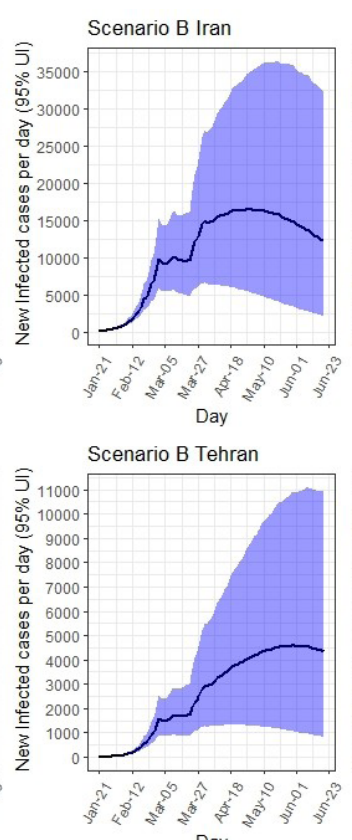

Day
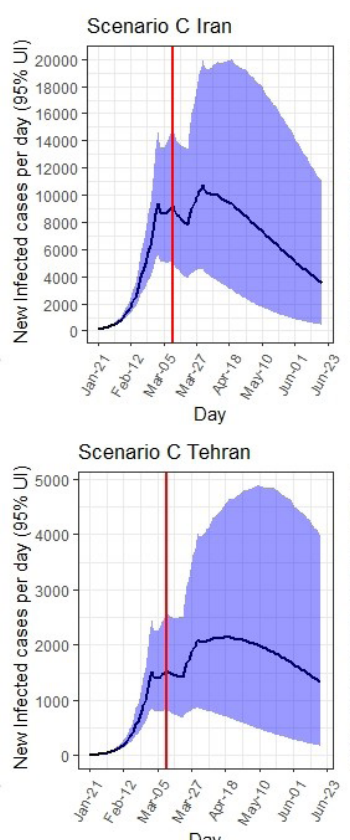

Day
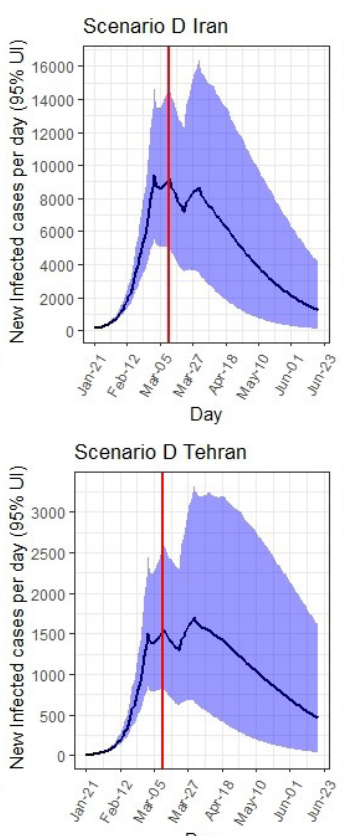

Day
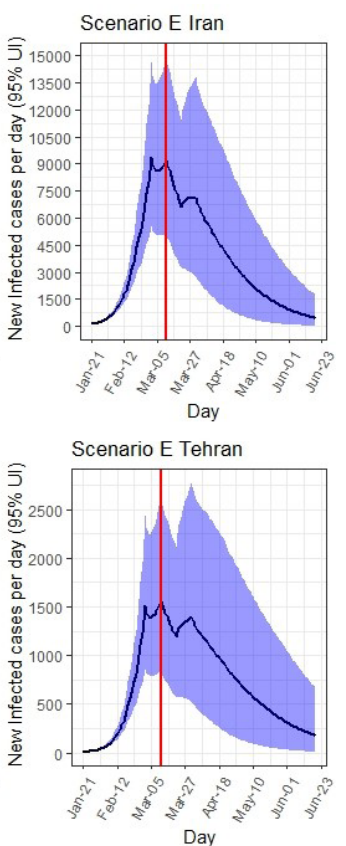

Figure 4. The Estimated Number of New Infected Cases Per Day in Iran and Tehran Under 5 Different Isolation Scenarios From January 21,2020 to June $19,2020$. The red line refers to the time when interventions were implemented and the blue area corresponds to Uls. Abbreviation: UI, uncertainty interval.

in Tehran would peak on June 19, 2020 at around $19000(95 \%$ UI: 5000-36000). Total number of infected cases by June 19 is expected to be 1228000 (95\% UI: 416400 to 2407000). The number of new cases at peak and total number of cases decreased to lowest number from scenario B to E. Under scenario $\mathrm{E}$, the number of new cases per day would reduce to 1600 (95\% UI: 900-2600), and the total number of infected cases by June 19 would reduce to 106400 (95\% UI: $41200-$ 225000) (Table 2, Figure 4).

\section{Expected Number of Hospitalized Cases}

Iran: Under scenario A, the number of hospitalized cases would peak on June 19 at around 67800 (95\% UI: 25100 $131000)$ per day. Total number of hospitalized cases by June 19 is expected to be 966000 (95\% UI: 467800-1702000). Under scenario B, the peak would occur on May 12 at around 14600 hospitalized cases a day. Under scenario C, the peak would occur on April 14 at around 7800 hospitalized cases a day. The number of hospitalized cases at the peak time under scenario D was 6600 cases (on March 15) and under scenario E was 6500 cases (on March 14).

Tehran: Under scenario A, the number of hospitalized cases per day in Tehran would peak on June 19 at around 19000 (95\% UI: 7800-34200). Total number of hospitalized cases by June 19 is expected to be 228000 (95\% UI: 108 800-400 800). The number of hospitalized cases at peak and total number of hospitalized cases are decreased to lowest number from scenario B to E. Under scenario E, the number of hospitalized cases per day decreases to 1000 (95\% UI: 500-1800), and the total number of hospitalized cases by June 19 decreases to 14000 (95\% UI: 4900-29700) (Table 2, Figure 5).

Expected Number of Deaths

Iran: Up to June 19, the total expected number of deaths would range from 111000 (95\% UI: 53400 to 200000$)$ under scenario A to 7800 (95\% UI: 3200-15000) under scenario E. The corresponding IFR under scenario A is $2.2 \%$, which would decrease to $1.4 \%$ under scenario E.

Tehran: Up to June 19, the total expected number of deaths would range from 25800 (95\% UI: 12000 to 47000 ) under scenario A to 1500 (95\% UI: 500 to 3000) under scenario E. The corresponding IFR under scenario A is $2.1 \%$, which would decrease to $1.3 \%$ under scenario E (Table 2, Figure 6).

Reproduction Number ( $\mathrm{R}$ )

At the begging of the epidemic, the $\mathrm{R}_{\mathrm{e}}$ was expectedly higher (ie, 4.70 for Tehran and 4.40 for Iran in scenario A to 3.93 in Tehran and 3.64 for Iran in scenarios B-E). The $\mathrm{R}_{e}$ decreased slightly by the end of the modeling process. From April 1 to July 19, the reproduction number was calculated as 1.18 in scenario A to 0.64 in scenario E (Table 3, Figure 7).

\section{Discussion}

Our results suggested that with no intervention (ie, scenario A), more than 5 million SARS-CoV-2 (severe acute respiratory syndrome coronavirus 2) infections (ie, $6.3 \%$ of total population) would occur in Iran till mid-June, of whom $18.9 \%$ would be hospitalized and $2.1 \%$ would die. However, under the best-case scenario (ie, scenario E), the number of infected patients, hospitalizations, and deaths could be reduced by $90 \%, 92 \%$, and $93 \%$, respectively. Our projection in scenario $\mathrm{C}$, which is a middle-ground scenario, appeared to be aligned with the current national trend in reported cases. Even under scenario C, the burden of the epidemic in Iran will be large, last for several months, yet might not surpass the healthcare system's capacity.

Based on the reported deaths and peak date for the number of confirmed cases per day, scenarios C or D are the most 
Table 2. The Estimated Date for Epidemic Peak, Number of Infected, Hospitalized, and Deceased Patients in Iran and Tehran Under 5 Different Scenarios From January 21, to June 19, 2020

\begin{tabular}{|c|c|c|c|c|c|c|c|c|c|c|}
\hline & \multicolumn{2}{|c|}{ Scenario A } & \multicolumn{2}{|c|}{ Scenario B } & \multicolumn{2}{|c|}{ Scenario C } & \multicolumn{2}{|c|}{ Scenario D } & \multicolumn{2}{|c|}{ Scenario E } \\
\hline & Iran & Tehran & Iran & Tehran & Iran & Tehran & Iran & Tehran & Iran & Tehran \\
\hline \multicolumn{11}{|c|}{ Infected Cases } \\
\hline Peak date & 9-Jun & 19-Jun & 30-Apr & 30-May & 31-Mar & 20-Apr & 1-Mar & 31-Mar & 1-Mar & 11-Mar \\
\hline $\begin{array}{l}\text { Number ( } 95 \% \text { UI) of new } \\
\text { cases per day on peak }\end{array}$ & $\begin{array}{c}66000 \\
(15600,145000)\end{array}$ & $\begin{array}{c}19000 \\
(5000,36000)\end{array}$ & $\begin{array}{c}16500 \\
(5400,35000)\end{array}$ & $\begin{array}{c}4600 \\
(1000,11000)\end{array}$ & $\begin{array}{c}10700 \\
(4600,20000)\end{array}$ & $\begin{array}{c}2200 \\
(700,4700)\end{array}$ & $\begin{array}{c}9400 \\
(5600,15000)\end{array}$ & $\begin{array}{c}1700 \\
(700,3300)\end{array}$ & $\begin{array}{c}9400 \\
(5600,15000)\end{array}$ & $\begin{array}{c}1600 \\
(900,2600)\end{array}$ \\
\hline $\begin{array}{l}\text { Total number (95\% UI) } \\
\text { until June 19, } 2020\end{array}$ & $\begin{array}{c}5196000 \\
(1753000 \\
10220000)\end{array}$ & $\begin{array}{l}1228000 \\
(416400 \\
2407000)\end{array}$ & $\begin{array}{l}1643300 \\
(603400 \\
3380000)\end{array}$ & $\begin{array}{c}398600 \\
(131000 \\
852000)\end{array}$ & $\begin{array}{c}949600 \\
(368000 \\
1960000)\end{array}$ & $\begin{array}{l}211800 \\
(71700, \\
467700)\end{array}$ & $\begin{array}{c}689000 \\
(286000 \\
1363000)\end{array}$ & $\begin{array}{l}142000 \\
(51200 \\
309800)\end{array}$ & $\begin{array}{c}550000 \\
(243500 \\
1070200)\end{array}$ & $\begin{array}{l}106400 \\
(41200 \\
225000)\end{array}$ \\
\hline \multicolumn{11}{|c|}{ Hospitalized Cases } \\
\hline Peak date & 19-Jun & 19-Jun & 12-May & 10-Jun & 14-Apr & 28-Apr & 15-Mar & 10-Apr & 14-Mar & 15-Mar \\
\hline $\begin{array}{l}\text { Number ( } 95 \% \mathrm{UI} \text { ) of the } \\
\text { existing cases on peak }\end{array}$ & $\begin{array}{c}67800 \\
(25100,131000)\end{array}$ & $\begin{array}{c}19000 \\
(7800,34200)\end{array}$ & $\begin{array}{c}14600 \\
(5800,28100)\end{array}$ & $\begin{array}{c}4000 \\
(1200,8600)\end{array}$ & $\begin{array}{c}7800 \\
(3200,14500)\end{array}$ & $\begin{array}{c}1600 \\
(550,3400)\end{array}$ & $\begin{array}{c}6600 \\
(3500,10900)\end{array}$ & $\begin{array}{c}1100 \\
(400,2100)\end{array}$ & $\begin{array}{c}6500 \\
(3400,10600)\end{array}$ & $\begin{array}{c}1000 \\
(500,1800)\end{array}$ \\
\hline $\begin{array}{l}\text { Total number (95\% UI) } \\
\text { until June } 19,2020\end{array}$ & $\begin{array}{c}966000 \\
(467800 \\
1702000)\end{array}$ & $\begin{array}{r}228000 \\
(108800 \\
400800)\end{array}$ & $\begin{array}{c}279500 \\
(119200 \\
527700)\end{array}$ & $\begin{array}{c}65500 \\
(26100 \\
127700)\end{array}$ & $\begin{array}{l}147000 \\
(56200, \\
292300)\end{array}$ & $\begin{array}{c}32000 \\
(11000 \\
67700)\end{array}$ & $\begin{array}{c}98700 \\
(38100 \\
195600)\end{array}$ & $\begin{array}{l}20000 \\
(6700, \\
42700)\end{array}$ & $\begin{array}{c}74500 \\
(29400 \\
146500)\end{array}$ & $\begin{array}{l}14000 \\
(4900, \\
29700)\end{array}$ \\
\hline $\begin{array}{l}\text { Total number (95\% UI) } \\
\text { until June 19, } 2020\end{array}$ & $\begin{array}{c}111000 \\
(53400,200000)\end{array}$ & $\begin{array}{c}25800 \\
(12000,47000)\end{array}$ & $\begin{array}{c}32900 \\
(14700,62000)\end{array}$ & $\begin{array}{c}7600 \\
(3100,15000)\end{array}$ & $\begin{array}{c}17700 \\
(7300,34400)\end{array}$ & $\begin{array}{c}3800 \\
(1400,7900)\end{array}$ & $\begin{array}{c}11000 \\
(4500,21700)\end{array}$ & $\begin{array}{c}2200 \\
(800,4600)\end{array}$ & $\begin{array}{c}7800 \\
(3200,15000)\end{array}$ & $\begin{array}{c}1500 \\
(500,3000)\end{array}$ \\
\hline Total IFR & $2.2 \%$ & $2.1 \%$ & $2.0 \%$ & $1.9 \%$ & $1.9 \%$ & $1.8 \%$ & $1.6 \%$ & $1.5 \%$ & $1.4 \%$ & $1.3 \%$ \\
\hline
\end{tabular}

Abbreviations: UI, Uncertainty Interval; IFR, infection fatality rate. 

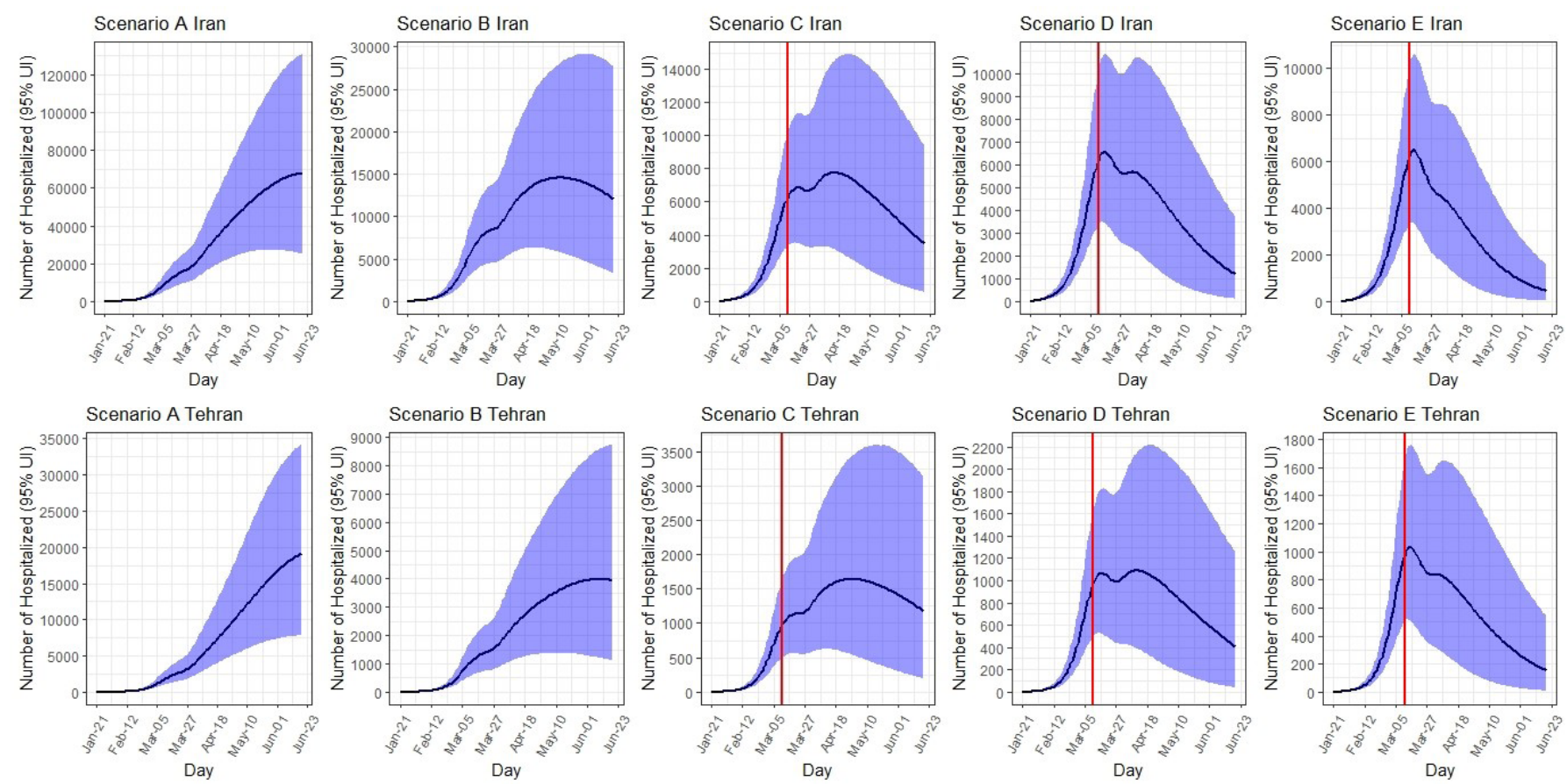

Figure 5. The Estimated Number of Existing Hospitalized Cases in Iran and Tehran Under 5 Different Isolation Scenarios From January 21, 2020 to June 19, 2020. The red line refers to the time when interventions were implemented and the blue area corresponds to Uls. Abbreviation: UI, uncertainty interval.
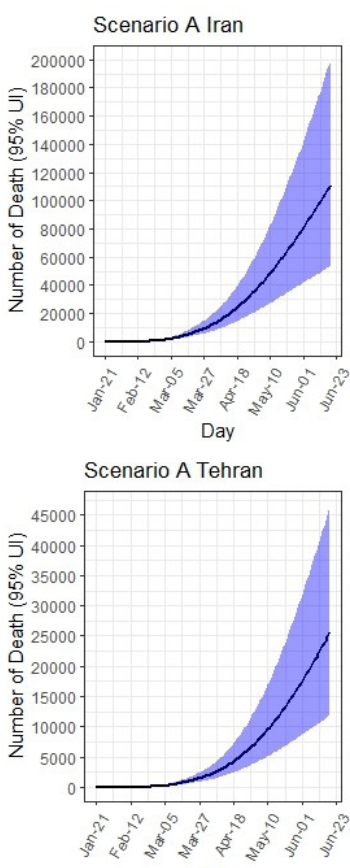

Day

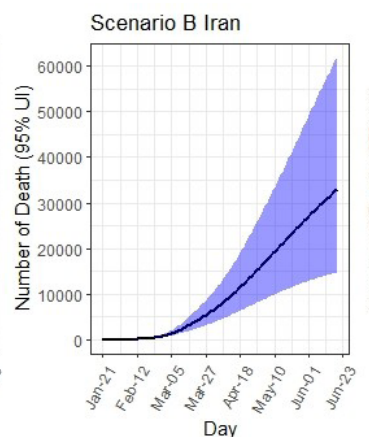

Day

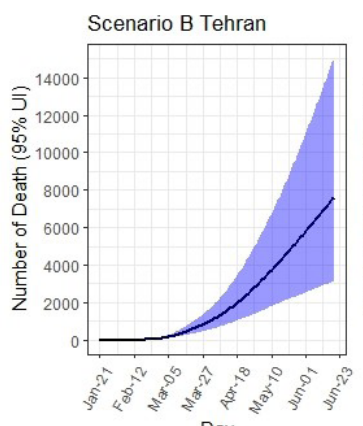

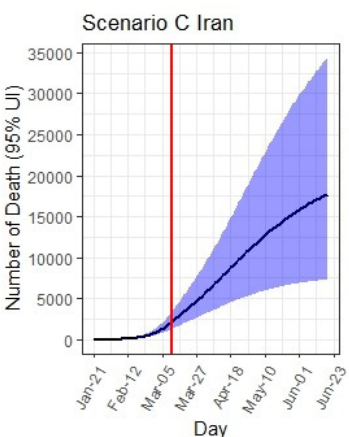

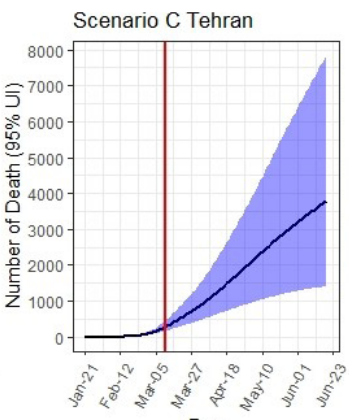

Day
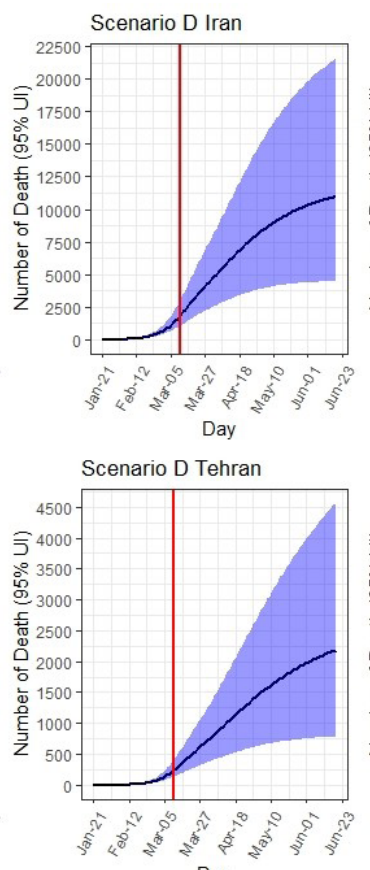

Day
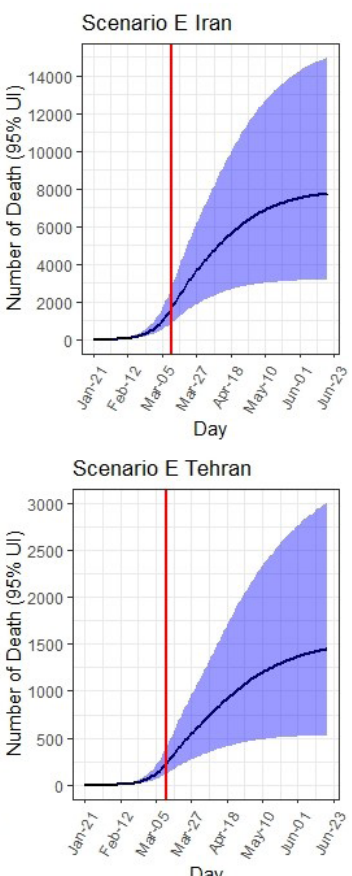

Figure 6. The Estimated Number of Deaths in Iran and Tehran Under 5 Different Isolation Scenarios From January 21, 2020 to June $19,2020$. The red line refers to the time when interventions were implemented and the blue area corresponds to Uls. Abbreviation: UI, uncertainty interval.

plausible ones for COVID-19 outbreak evolvement in Iran. Under scenario C, 10100 new infections would have occurred on April 5, 2020, which is four times the number of confirmed cases on that date. This scenario expects the total number of infections and deaths by mid-June to be around 950000 and 17600 , respectively; more than two times the number of observed deaths to date (ie, 8209 cases by June 6, 2020). Our findings however, suggest that scenario B is the most plausible scenario in the capital city of Tehran which highlights the importance of implementing special measures and policies in this city to reduce the spread of the disease. Our findings in scenario B are comparable with other dynamic model estimations in Iran, ${ }^{21}$ that have predicted around 1.6 million (90\% CI, 0.9 million-2.6 million) cases, and 58000 (90\% CI, 32 000-97 000) deaths under their most optimistic scenarios. The above-mentioned model however, had three structural 
Table 3. Reproduction Number of the Virus in Tehran and Iran Based on Different Isolation Scenarios From January 21, 2020 to July 19, 2020

\begin{tabular}{|c|c|c|c|}
\hline Time Intervals & Scenario & $\mathbf{R}_{\mathrm{e}}$ for Tehran & $R_{e}$ for Iran \\
\hline \multirow{5}{*}{$\begin{array}{l}\text { Jan 21, } 2020 \text { to Jan 30, } \\
2020\end{array}$} & A & 4.70 & 4.40 \\
\hline & B & 3.93 & 3.64 \\
\hline & $C$ & 3.93 & 3.64 \\
\hline & $\mathrm{D}$ & 3.93 & 3.64 \\
\hline & $E$ & 3.93 & 3.64 \\
\hline \multirow{5}{*}{$\begin{array}{l}\text { Jan 31, } 2020 \text { to Feb 9, } \\
2020\end{array}$} & A & 4.31 & 3.97 \\
\hline & $B$ & 3.56 & 3.29 \\
\hline & $C$ & 3.56 & 3.29 \\
\hline & $D$ & 3.56 & 3.29 \\
\hline & $E$ & 3.56 & 3.29 \\
\hline \multirow{5}{*}{$\begin{array}{l}\text { Feb 10, } 2020 \text { to Feb 19, } \\
2020\end{array}$} & A & 3.88 & 3.56 \\
\hline & B & 3.22 & 2.95 \\
\hline & C & 3.22 & 2.95 \\
\hline & $D$ & 3.22 & 2.95 \\
\hline & $E$ & 3.22 & 2.95 \\
\hline \multirow{5}{*}{$\begin{array}{l}\text { Feb 20, } 2020 \text { to Feb 29, } \\
2020\end{array}$} & A & 3.16 & 2.84 \\
\hline & B & 2.39 & 2.15 \\
\hline & $C$ & 2.39 & 2.15 \\
\hline & $D$ & 2.39 & 2.15 \\
\hline & $E$ & 2.39 & 2.15 \\
\hline \multirow{5}{*}{$\begin{array}{l}\text { Mar 1, } 2020 \text { to Mar 10, } \\
2020\end{array}$} & A & 2.31 & 2.31 \\
\hline & B & 1.15 & 1.15 \\
\hline & $C$ & 1.15 & 1.15 \\
\hline & D & 1.15 & 1.15 \\
\hline & $E$ & 1.15 & 1.15 \\
\hline \multirow{5}{*}{$\begin{array}{l}\text { Mar 10, } 2020 \text { to Mar 20, } \\
2020\end{array}$} & $A$ & 1.46 & 1.46 \\
\hline & B & 1.21 & 1.21 \\
\hline & $\mathrm{C}$ & 1.03 & 1.03 \\
\hline & $D$ & 0.89 & 0.89 \\
\hline & $E$ & 0.79 & 0.79 \\
\hline \multirow{5}{*}{$\begin{array}{l}\text { Mar 21, 2020, to Mar 31, } \\
2020\end{array}$} & A & 1.68 & 1.68 \\
\hline & B & 1.39 & 1.39 \\
\hline & C & 1.18 & 1.18 \\
\hline & $D$ & 1.03 & 1.03 \\
\hline & $E$ & 0.91 & 0.91 \\
\hline \multirow{5}{*}{$\begin{array}{l}\text { Apr 1, } 2020 \text { to June } 19 \text {, } \\
2020\end{array}$} & A & 1.18 & 1.18 \\
\hline & $B$ & 0.98 & 0.98 \\
\hline & $C$ & 0.84 & 0.84 \\
\hline & $D$ & 0.73 & 0.73 \\
\hline & $E$ & 0.64 & 0.64 \\
\hline
\end{tabular}

assumptions on three major parameters (ie, duration of illness as 14 days, asymptomatic period as 4 days, and transmission probability as 0.25 during the asymptomatic period) and did not account for seasonality distribution. ${ }^{21}$

Our model indicated that under scenario $\mathrm{C}$ (ie, the best fitted trend with reported cases/deaths), Iran might have sufficient hospital bed capacity for COVID-19. As of April 8, 2020, public hospitals in Iran, which are mainly responsible for the COVID-19 response, had 146137 beds (9134 in intensive care units [ICU] and 9730 ventilators). By discharging inpatient cases and postponing elective medical care and surgeries, Iran has currently allocated 100437 empty beds, 5790 empty ICU beds, and 4650 ventilators towards COVID-19 patients. This might be sufficient for sever COVID-19 patients as predicted by scenario $\mathrm{C}$ which would still require appropriate supplies and staffing. As of April 8, 2020, there were 0.41 physician and 1.14 nurse per public hospital bed in Iran. Even under scenario $\mathrm{C}$, the shortage of healthcare workers would be challenging, although there are sufficient beds and ventilators.

Our model showed that non-pharmaceutical innervations actually worked to control the epidemic in Iran. In addition to individual- and community-level physical distancing control measures that have been implemented in Iran from late February to late March, the number of testing for COVID-19 screening was also increased from 1000 tests per day on March 12, 2020 to about 20000 tests per day on May 27, 2020. This has led to an increase in case finding, contact tracing of new cases, and isolation of confirmed cases. Despite the persistent increase in testing, the number of confirmed cases per day peaked at 3200 on March 30, 2020 and then decreased to 1374 cases per day on April 18, 2020. ${ }^{22}$ Moreover, measuring the real intensity and coverage of physical distancing in Iran is challenging as these practices have not been closely followed during to the new year (ie, Nowruz) holidays between March 19 and 26, 2020.23,24 Such a significant increase in travels made the government to enforce physical distancing by lockdown, and closing the roads. While we did account for the Nowruz effect in our model by increasing the number of contacts per day (parameter C) from 5 to 6 from March 21 to March 31, 2020, the true effect of Nowruz on the current and future

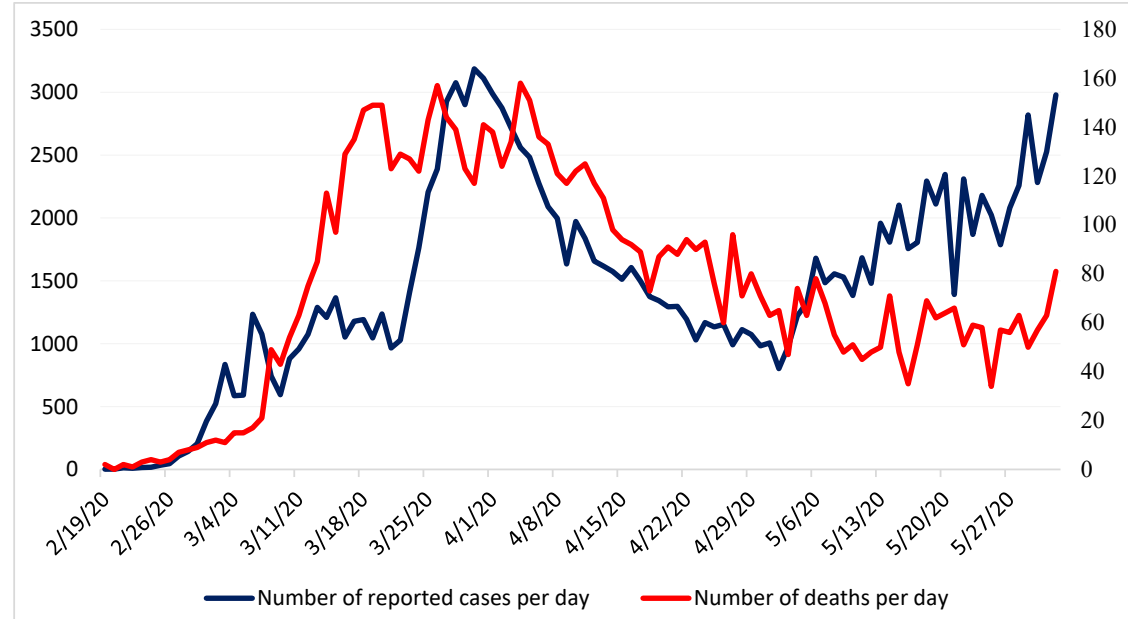

Figure 7. The Number of Reported Cases and Deaths Per Day From the Begging of the Epidemic to June 1, 2020 in Iran. 
projected numbers remains unknown.

Our projections of the COVID-19 morbidity and mortality in Iran under different physical distancing and isolation scenarios are insightful for government's policies regarding relaxing the physical distancing and isolation interventions. Although the decision on the timing of and approaches towards lifting the physical distancing restrictions is extremely difficult and varies across countries with different economic and healthcare infrastructures, it is critical to follow an evidence-informed approach to avoid the second and further waves of COVID-19 epidemics in Iran. A modeling study from China for example, ${ }^{25}$ showed that a stepwise $(25 \%$ of the workforce working in weeks 1 to $2,50 \%$ of the workforce working in weeks 3 to 4 , and $100 \%$ of the workforce working and school resuming from week 5 forward) return to work or school at the beginning of April (about 5 months after the first case reported from China), is much more effective than the beginning of March. This study estimated that just a onemonth delay in the stepwise lifting of the physical distancing measures would reduce the magnitude ( $92 \%$ by mid- 2020 , $24 \%$ by end-2020) the epidemic and delay its peak by two months and therefore avoid overwhelming the healthcare systems. ${ }^{25}$

In Iran, the daily number of cases declined for a few weeks in April, but the second wave of the epidemic is emerging. A recent executive order from the Iranian government lifted the restrictions on nationwide business shutdown and allowed most people to return to work only 2.5 months after the identification of the first COVID-19 case in Iran. ${ }^{9,26}$ The government has also planned to reopen schools in low-risk cities and non-essential low or medium-risk jobs (eg, all production units in industrial, business, technical service, and distributional sections), as well as removing the shelterin-place order and resuming domestic and international travels. These decisions are mainly derived from the Iranian government's economic challenges that have been elevated by the comprehensive sanctions imposed by the United States. ${ }^{27,28}$ While these concerns are understandable and longer shutdown of an already overstretched economy is a tough decision and would be very taxing on the government and the public, our findings as well as lessons learned from China, ${ }^{25,29,30}$ suggest that this approach might not be justified by evidence and would most likely risk overwhelming the healthcare systems with the next waves of COVID-19 epidemic in Iran; costs that might surpass the marginal economic benefits of opening businesses and schools a few months sooner. Nonetheless, it is fortunate that the Iranian Center for Disease Control is now planning to shift from physical distancing to targeted case-finding, intensify contact tracing and careful isolation of identified cases as well as self-quarantine of symptomatic people.

Our study had three major limitations. First, some of the key parameters (eg, hospitalization rate, incubation period, transmission probability) that were used in the model were from other countries or expert opinion as empirical data from Iran were unavailable. To address this limitation, we reported a range of UIs. Second, the UIs are fairly wide for most of our results which resulted from the uncertainty in model parameters. Third, our projection for the course of the epidemic in the coming months in Iran is based on the assumption we made about implementing and sustaining the physical distancing as planned, and any changes in policy and public interventions may change the course of the epidemic. Despite these limitations, our results under different scenarios provide a foundation to measure the effect of interventions that are ongoing in the country.

\section{Conclusion}

With no available vaccination, prophylaxis or therapy, we found physical distancing and isolation that includes public awareness and case finding and isolation of $40 \%$ of the infected cases could reduce the burden of COVID-19 in Iran by $90 \%$ by mid-June. The IFR for the national model ranged from $1.4 \%-2.2 \%$.

\section{Ethical issues}

The proposal of the present study was approved by ethics committee of Kerman University of Medical Sciences, Kerman, Iran (reference 98001239).

\section{Competing interests}

The senior author, AAH is the Deputy Minister of Education and the Head of National Committee on COVID-19 Epidemiology. The rest of the authors declare no conflict of interest, real or perceived.

\section{Authors' contributions}

In this work HS, YJ, AM, MAG, and MN took the lead, were responsible for the data analysis and made substantial contributions to conception, design, and writing. MS, SE, HRT, and MK made substantial contributions to conception, design, and writing. EM, DK, and SSHN revised the study critically and contributed to conception. $\mathrm{AAH}$ revised the study critically, contributed substantially to conception, design, the interpretation of data, and drafting of the article.

\section{Funding}

The study did not receive any funding from any organization.

\section{Authors' affiliations}

${ }^{1}$ HIVISTI Surveillance Research Center, and WHO Collaborating Center for HIV Surveillance, Institute for Futures Studies in Health, Kerman University of Medical Sciences, Kerman, Iran. ${ }^{2}$ Department of Biostatistics and Epidemiology, School of Public Health, Kerman University of Medical Sciences, Kerman, Iran. ${ }^{3}$ Modeling in Health Research Center, Institute for Futures Studies in Health, Kerman University of Medical Sciences, Kerman, Iran. ${ }^{4}$ Department of Epidemiology and Biostatistics, Institute for Global Health Sciences, University of California San Francisco, San Francisco, CA, USA. ${ }^{5}$ Dalla Lana School of Public Health, University of Toronto, Toronto, ON, Canada. ${ }^{6}$ Department of Epidemiology and Biostatistics, Research Centre for Emerging and Reemerging Infectious Diseases, Pasteur Institute of Iran, Tehran, Iran. ${ }^{7}$ Prevention of Metabolic Disorders Research Center, Research Institute for Endocrine Sciences, Shahid Beheshti University of Medical Sciences, Tehran, Iran. ${ }^{8}$ Prevention of Cardiovascular Disease Research Center, Department of Epidemiology, School of Public Health and Safety, Shahid Beheshti University of Medical Sciences, Tehran, Iran. ${ }^{9}$ School of Population and Public Health, Faculty of Medicine, University of British Columbia, Vancouver, BC, Canada.

\section{Supplementary files}

Supplementary file 1 . The SEIR Model.

Supplementary file 2 contains Tables S1 and S2.

Supplementary file 3. Calculation of Reproduction Number $\left(R_{0}\right)$.

\section{References}

1. COVID-19 Coronavirus Pandemic. Worldometers website. https:// www.worldometers.info/coronavirus/. 
2. Daily Situation Report on Coronavirus disease (COVID-19) in Iran; June 5, 2020. http://corona.behdasht.gov.ir/files/site1/files/IRAN_ COVID19 Factsheet N.44 -6June En.pdf.

3. World Health Organization (WHO). Eastern Mediterranean Region COVID-19 Affected Countries. https://cutt.ly/ha70MOP. Accessed April 13, 2020.

4. Trottier H, Philippe P. Deterministic modeling of infectious diseases: applications to measles and other similar infections. Internet $J$ Infect Dis. $2001 ; 2(1): 1-10$

5. Lekone PE, Finkenstädt BF. Statistical inference in a stochastic epidemic SEIR model with control intervention: Ebola as a case study. Biometrics. 2006;62(4):1170-1177. doi:10.1111/j.15410420.2006.00609.x

6. Wearing $\mathrm{HJ}$, Rohani $\mathrm{P}$, Keeling MJ. Appropriate models for the management of infectious diseases. PLoS Med. 2005;2(7):e174. doi:10.1371/journal.pmed.0020174

7. Community-Based Measures to Mitigate the Spread of Coronavirus Disease (COVID-19) in Canada. https://www.canada.ca/en/publichealth/services/diseases/2019-novel-coronavirus-infection/healthprofessionals/public-health-measures-mitigate-covid-19.html\#cbm. Accessed April 10, 2020.

8. Centers for Disease Control and Prevention (CDC). Social Distancing, Quarantine, and Isolation. https://www.cdc.gov/coronavirus/2019ncov/prevent-getting-sick/social-distancing.html. Accessed April 8, 2020.

9. Daily Situation Report on Coronavirus disease (COVID-19) in Iran; April 11, 2020. http://corona.behdasht.gov.ir/files/site1/files/ Factsheet21.23.01-En.pdf. Accessed April 11, 2020.

10. Haghdoost AA, Gooya MM, Baneshi MR. Modelling of H1N1 flu in Iran. Arch Iran Med. 2009;12(6):533-541.

11. Arregui S, Aleta A, Sanz J, Moreno Y. Projecting social contact matrices to different demographic structures. PLoS Comput Biol. 2018;14(12):e1006638. doi:10.1371/journal.pcbi.1006638

12. Mossong J, Hens $\mathrm{N}$, Jit $\mathrm{M}$, et al. Social contacts and mixing patterns relevant to the spread of infectious diseases. PLoS Med. 2008;5(3):e74. doi:10.1371/journal.pmed.0050074

13. Ibuka $Y$, Ohkusa $Y$, Sugawara $T$, et al. Social contacts, vaccination decisions and influenza in Japan. J Epidemiol Community Health. 2016;70(2):162-167. doi:10.1136/jech-2015-205777

14. Hoang T, Coletti P, Melegaro A, et al. A systematic review of social contact surveys to inform transmission models of close-contact infections. Epidemiology. 2019;30(5):723-736. doi:10.1097/ ede.0000000000001047

15. Prem K, Cook AR, Jit M. Projecting social contact matrices in 152 countries using contact surveys and demographic data. PLoS Comput Biol. 2017;13(9):e1005697. doi:10.1371/journal.pcbi.1005697

16. Keeling MJ, Rohani P. Modeling Infectious Diseases in Humans and Animals. Princeton: Princeton University Press; 2011.
17. Vynnycky E, White RG. An Introduction to Infectious Disease Modelling. Oxford: Oxford University Press; 2010.

18. van den Driessche P, Watmough J. Reproduction numbers and subthreshold endemic equilibria for compartmental models of disease transmission. Math Biosci. 2002;180:29-48. doi:10.1016/s00255564(02)00108-6

19. COVID-19 Coronavirus / Death Rate. Worldometer website. https:// www.worldometers.info/coronavirus/coronavirus-death-rate/. Published May 14, 2020.

20. Carcione JM, Santos JE, Bagaini C, Ba J. A simulation of a COVID-19 epidemic based on a deterministic SEIR model. Front Public Health 2020;8:230. doi:10.3389/fpubh.2020.00230

21. Ghaffarzadegan N, Rahmandad H. Simulation-based estimation of the spread of COVID-19 in Iran. medRxiv. 2020. doi:10.1101/2020.03.22.20040956

22. Daily Situation Report on Coronavirus disease (COVID-19) in Iran; April 18, 2020. http://corona.behdasht.gov.ir/files/site1/files/IRAN COVID19_Factsheet_N.26_-18April_En.pdf. Accessed April 18, 2020.

23. Coronavirus: Iranians Urged to Stay Home During Holiday. BBC. March 19, 2020. https://www.bbc.com/news/world-middleeast-51968774. Accessed April 8, 2020.

24. Iranian Press Review: Iranians Ignore Coronavirus Travel Warning Ahead of Nowruz Holiday. Middle East Eye website. https://www. middleeasteye.net/news/iran-press-review-coronavirus-nowruztravel-warning-ignore. Accessed April 10, 2020.

25. Prem K, Liu Y, Russell TW, et al. The effect of control strategies to reduce social mixing on outcomes of the COVID-19 epidemic in Wuhan, China: a modelling study. Lancet Public Health. 2020;5(5):e261-e270. doi:10.1016/s2468-2667(20)30073-6

26. Iran Reports its First 2 Cases of the New Coronavirus. The Times of Israel. February 19, 2020. https://www.timesofisrael.com/iran-reportsits-first-2-cases-of-the-new-coronavirus/. Accessed April 10, 2020.

27. Healthcare Worker in Iran Discusses Effects of U.S. Sanctions. NPR website. https://www.npr.org/2019/06/26/736344054/healthcareworker-in-iran-discusses-effects-of-u-s-sanctions. Accessed April 11, 2020.

28. Danaei G, Harirchi I, Sajadi HS, Yahyaei F, Majdzadeh R. The harsh effects of sanctions on Iranian health. Lancet. 2019;394(10197):468469. doi:10.1016/s0140-6736(19)31763-5

29. Ferguson NM, Laydon D, Nedjati-Gilani G, et al. Impact of non-pharmaceutical interventions (NPIs) to reduce COVID-19 mortality and healthcare demand. Imperial College London; 2020. doi:10.25561/77482

30. Jia J, Ding J, Liu S, et al. Modeling the control of COVID-19: impact of policy interventions and meteorological factors. arXiv200302985. 2020. 